\title{
Morbidezza Power: Initial Probe into Cultural Studies on Feminine Role in American Civil Society
}

\author{
Lin Li \\ College of Foreign Languages and Cultures, Sichuan University, Chengdu 610000, China \\ 577614320@qq.com
}

\begin{abstract}
In comparison with Europe, the birthplace of the concept of Civil Society, American society has not undergone the twists and turns in terms of developments in Civil Society. In addition to the preparation in political systems, stimulation by founding Constitutions, promotion from citizens' religious faith, feminine movement has played an indispensable role, which has always been ignored. Adopting the analytic paradigm of Public Space and examples of society activities in feminine movement, this paper attempts to aim at interpreting feminine role in the development of American civil society.
\end{abstract}

Keywords: American Feminine Movement; Civil Society; Public Space; Cultural Studies

\section{柔美的力量：美国市民社会中的女性角色的文化研究初探}

\author{
李 琳 \\ 四川大学外国语学院，成都 中国
}

摘要：“市民社会”在美国的发展，较之其起源之地的欧洲，未曾经历过多的曲折过程。除 却政治制度的准备，建国宪章的促进作用，人们宗教信仰的推动，女性运动在此期间也起到 了不可或缺的作用, 而女性角色在美国市民社会的发展中的作用却往往被忽视。本文从公共 领域的分析范式入手，择取女性运动的社团活动的实例，初步阐释女性角色在美国市民社会 发展中的作用。

关键词：美国女性运动；市民社会；公共领域；文化研究

\section{1. 前言}

市民社会 (civil society) 这一概念是一个常话常新的议题, 其起源由来已久, 肇始于古 希腊的城邦制社会，中间历经欧洲的民族国家和政治国家的检验和洗礼，为各个阶段的政治 哲学家们提供了丰富的素材, 而其概念的阐释却随着历史的进展发生了多次的演变。从最初 的作为 “国家共同体” 的市民社会, 到与政治国家分庭抗礼的 “公民群体” 的市民社会; 从 具有政治倾向的 “市民社会” 到 “文明化的商业社会” ; 从自然伦理形态的 “市民社会” 到 崇尚私有制的 “市民社会” ; 从资本主义的 “市民社会” 到批判资本主义的 “市民社会” ， 在其诞生之地的欧洲大陆, 市民社会这一概念并非是一躈而就的理论框架和概念, 而它在美 国的发展却并未经历如此跌宕起伏的发展过程。1776年，美利坚合众国发布《独立宣言》， 宣告殖民地各州脱离其母国, 其立国的根本就植根于 “平等自由” 这一天赋人权的理念之中。 市民社会的一个核心成分即 “文明化的自由民主的民众主体”，而这与美国的建国方针有着 相当的契合。因此，市民社会在美国的发展之初并未经历曲折，因为美国的清教徒精神之一 即是 “自我解放和自我管理” ，这点极其符合市民社会的 “市民自治” 的根本内容。即便如 此，被誉为 “共和国之母” 的美国妇女们在美国市民社会中的地位确立却并不是一帆风顺的。 从17世纪初北美殖民地开发到 20 世纪初美国宪法《第十九条修正案》正式通过的三百余年时 间, 美国妇女一直没有成为真正意义上的公民。作为参与美利坚合众国创建和发展并为之做 出重大贡献的社会群体, 她们在国家和社会各个层面受到了不自由不公正不平等地对待。美 
国妇女从默认现状、顺从屈服到心理反思、意识觉悟, 直至奋起反抗、不解斗争, 经过漫长 持久、艰苦卓绝的努力, 最终才以通过联邦宪法修正案的形式而获得了作为美国公民的政治 权利（王恩铭，2002：1）。美国妇女最终被 “赋予” 选举权等政治权利并不等同于她们就 从实际上获得与男性公民完全一致的待遇; 不论是在政治立场还是职场待遇抑或是经济地 位，妇女们仍然处于 “玻璃天花板”的笼罩之下。

对于这些已然存在的问题, 相关学者进行了分析并在著作中对此论题进行阐释。邓正来所编 的《国家与市民社会》一书汇集了中外学者研究市民社会的经典之作，可以全面了解市民社 会的概念、缘起、模式和研究路径, 对于市民社会的研究领域是一部最初应该掌握的基础之 作。《美国市民社会研究》是朱世达主编的一部呈现美国社会的市民生活状态的百科全书式 的著作。书中的文章从各个不同的角度来反映美国市民社会的全景式的缩略写照。文中的章 节包括阐述了 “美国市民社会与政治民主”，“宗教与美国市民社会”，“美国少数族裔的 政治参与”，“犹太社团”，“NPO在美国社会中的作用”，“NGO与美国对华人权外交” 等 等篇章从各个侧面折射出了美国市民社会的方方面面, 但是, 女性社团的发展历程、在社会 中功能与作用却未被独立成章, 只是杂糅在相关章节中进行了叙述。这样也是市民社会论著 中，妇女的作用被忽视的佐证之一。王浩斌的《市民社会的乌托邦》一书深刻指出了市民社 会作为一个公共领域, 有助于社会实现民主和公平; 然而若作为私人领域, 则是民主与公平 的破坏者。市民社会特征的这种两难境地使得市民社会的建立和完善之中实难分出对与错之 届。此书指出了市民社会的发展并不是一蹴而就, “乌托邦” 式的愿望与社会的现实之间的 差距一直存在着。美国的妇女运动在市民社会中的作用表现出来的 “维谷”之势, 实则市民 社会发展中的自然阶段。这对妇女运动朝着进深阶段的发展能有着理论引导之用。袁弋胭的 博士论文《19世纪英国中产阶级自愿社团研究》虽说研究的对象与本论文不属同一范畴, 但 是, 对于自愿社团的研究方向却为本论文提供了可借鉴的方式。王恩铭的《20世纪美国妇女 研究》对美国妇女运动进行提纲挈领式的总结, 系统研究了美国妇女运动在不同阶段的表现 方式和在社会中所起的功能。妇女运动按编年纪事的叙述方式给人很明晰的历史纵深感, 对 妇女运动的把握有着清晰的脉络。着眼于妇女运动中所建立的各个组织团体对于具体阐释妇 女运动与市民社会的发展关系也能提供有力的论据支撑。而周丽萍的《美国妇女与妇女运动

(1920-1939) 》将妇女运动的研究时期集中于两次世界大战之间的阶段, 指出妇女运动在 此时期的特点，与当时的特殊时期的市民社会当中各环节之间的联系，从社会、政治、经济 和家庭各方面对妇女运动进行全景式的概括。从历史的角度阐发的阶段性的妇女运动在市民 社会中的功能而言，这是一部很有借鉴意义的著作。

\section{2. 市民社会的女性 “被不在场” 的现象}

市民社会在美国的发展因为有着 “先天的” 优势条件，民众自治的市民社会的特征完美体现 在遍布市民阶层的各个社团, 担当起政府在民众中 “未竟” 或是 “不能竟”之事务。在这样 的市民社会中，市民恪守 “热爱你的邻居犹如爱你自己，热爱你的祖国甚于爱你自己” 的信 条。一切的迹象表明: 市民社会在美国比在欧洲发展得更完美。

诚然，除却所有的这些光环，美国的市民社会与欧洲市民社会一样，有一个致命的弊端，那 就是女性同样被排除在市民社会之外, 或者, 女性在争取自己正当的政治权利时, 需要经过 艰苦的抗争和努力。不论从家庭地位, 政治地位或是公共领域的地位, 女性都属于从属的, 被压迫的和被忽略的。在市民社会这一充满 “自然关爱和社会交往的领域” 中（Adam，1992： 3），她们是被 “出场” 的角色。

早期欧洲移民来到北美大陆时, 他们把欧洲的一些习俗也 “移植” 了过来。在当时的欧洲和 北美, 法律条文和文化习俗都偏向男性, 轻视女性。不管女性的才华如何, 她们只能处于从 属于男性的位置。男性不仅有国家政治的大权在握, 而且还是家里的绝对权威。本杰明 - 华 兹沃思牧师 1712 年在《秩序井然的家庭》一书中的一段话, 最好不过地概括了当时女性所处 的地位。他这样劝告他的女性读者: “也许, 你比你的丈夫更聪明, 你的出身也更高贵, 而 
且, 结婚时你所带来的家产也比他的多, 但是, 既然他是你的丈夫, 上帝就理所应当地给了 他一家之长的地位, 让你从属于他。”（王恩铭, 2002：4）如果说殖民时期的妇女由于在 家庭经济中起着不可或缺的作用，因而有时还能在家庭范围内享有一定程度的平等地位的 话，那么她们的这种平等地位充其量也是相当有限的，仅仅是限于家庭这种 “私人领域”。 一旦走出狭小的家庭范围, 男女之间的任何程度的平等关系便不复存在。即使是那些拥有大 量财产且出生于豪门家族的妇女也难以享受政治权利, 遑论大众普通妇女。

\section{3. 美国市民社会中的女性抗争之路的代表形式}

市民社会的研究关注的是个人的身份建构，而女性角色在市民社会中的建立和完善与其政治 身份的确立息息相关。对此的文化研究则集中在女性身份在市民社会视角下的建构, 从选举 权到平等教育权到就业权等政治身份的权利，同时还包括生育权陌胎权反对暴力侵犯权等日 常生活各方面的权利。通过志同道合者的社团组织，美国妇女展现自我的力量。其中，“美 国的安置所运动” 和 “美国全国妇女组织” 就是其中的显著代表。

19世纪末 20 世纪初资本主义在美国的迅猛发展, 工业革命的大力推进，加快了城市化进程， 农业人口大量涌入，贫富悬殊加大，导致大批城市贫民出现。与此同时，因为社会上倡导的 “新女性” 运动, 一些家境良好的女子不愿意被传统角色所束缚, 他们不满足于仅在家中侍 奉男人和教导子女, 因此简 -亚当斯和朱莉娅・拉斯洛普等人积极组织参与了 “安置所运动”, 热心解决当时的社会问题。他们提供住房, 并为住房者提供公益教育而且兴办了幼儿园。运 动开始于芝加哥, 然后在辛辛那提等城市也发展成燎原之势。安置所运动发展到后期逐渐式 微, 这与当时的社会状况固然有一定联系, 但是也与女性运动的一定缺陷相关。这在本研究 的结论中会论及。

“美国全国妇女组织” 是在六十年代女权运动的鼎盛时期成立, 迄今为止它仍然是美国全国 范围内最有影响力的女性社团组织之一。与之前的很多妇女团体组织相比较, 它的组织架构 清晰, 规章制度严明, 机构功能健全, 运作机制完善, 这也是它能长久存在并持续在市民公 众生活中发挥作用的原因之一。

\section{4. 结论}

美国市民社会的 “公共领域” 的 “普适” 原则，同样适合于解释女性力量在市民社会的作用。 公共领域在女性团体组织中的重构, 深刻影响了女性社团运动的成败, 从而左右了其在市民 社会中的组成作用。

对于 “公共领域”，长期以来，业界评判其为是一个以肯定个人独立自由为前提、以形成公 共與论和公共理性为形式、以追求公共性（共识）为内容、以捍卫社会正义和保护私人权利 为目的的社会交往和文化批判领域（杨仁忠，2009：9）。它依托于市民社会、独立于政治 国家并介于二者之间，既认可政治国家的建制化安排又维护社会自由与权利，是政治国家制 度化运作不可或缺的辅助性结构。从市民社会诞生伊始，公共领域就与之相伴相生。随着市 民社会的概念的变迁, 公共领域的表现方式和体现的功能也有所差异。在其众多研究者中, 当属哈贝马斯的 “公共领域” 学说最具统领性, 并能充分展现公共领域从政治概念到学理范 式的一种转变。

美国市民社会中的妇女力量在公共领域中的特征从上述两个社团案例分析出发, 初步总结如 下:

紧扣时代背景, 顺应时代要求, 积极参与公众事务, 实现个人的自由平等并在整个社会产生 广泛的舆论影响, 形成了公共权力。

结构转型表现在市民社会中的女性组织的公共领域。女性团体初期的公共领域较为松散和随 意, 且无严格的规章制度的约束, 造成领导者与执行者之间并未形成有效的沟通机制。而在 女性团体完善的后期, 这些缺陷逐步得以克服。 


\section{References}

[1]. Cao, Weidong: Habermas in Weidong Cao’s Eyes, Beijing: Beijing University Press, 2005.

[2]. Cheng, Qing: Reimagination of State and Society: Debate on Civil Society (from Collapse of Enlightenment: Study on Major Debate in Chinese Intellectuals since 1990), Changchun: Jilin Press Co. 2007.

[3]. Detlef Horster: Habermas, Lu Lu (trans.) Beijing: Renmin University of China Press, 2010.

[4]. Deng, Zhenglai: State and Civil Society, Beijing: Central Compilation \& Translation Press, 2002.

[5]. Habermas: Structural Tranformation in the Public Sphere, Cao Weidong (trans.), Shanghai: Academia Press, 1999.

[6]. Li, Dianlai: Public Sphere and Life World: Study on Habermasian Civil Society Theory, Beijing: People's Press, 2006.

[7]. Wang, Enming: Study on 20th Century American Wome, Shanghai: Shanghai Foreign Language Education Press, 2002.

[8]. Wang, Haobin: Utopia in Civil Society, Nanjing: Phoenix Publishing \& Media, 2011.

[9]. Yang, Renzhong: On Public Sphere, Beijing: People’s Press, 2009.

[10]. Yang, Shengmao ect. : New Edition of American History, Beijing: Renmin University of China Press, 1990.

[11]. Yu, Keping: Inremental Democracy and Good Governance, Beijing: Social Sciences Academic Press, 2003 